International Journal of Maternal and Child Health and AIDS (202I), Volume I0, Issue I, 70-80

\begin{tabular}{ll}
\hline & INTERNATIONAL JOURNAL of \\
& MATERNAL and CHILD HEALTH and AIDS \\
& ISSN 216I-864X (Online) \\
& ISSN 216I-8674 (Print) \\
& DOI: 10.21 I 06/ijma.407 \\
\hline
\end{tabular}

ORIGINAL ARTICLE | CHILD HEALTH

\title{
Urogenital Schistosomiasis among Primary School Children in Rural Communities in Obudu, Southern Nigeria
}

\author{
Kenneth N. Opara, PhD;' Rebecca T. Akomalafe, MSc;' Nsima I. Udoidung, PhD;' Udeme U.Afia, PhD;' \\ Clement A. Yaro, MSc; ${ }^{1,2 * \bowtie}$ Bassey E. Bassey, MSc' \\ 'Department of Animal and Environmental Biology, Faculty of Science, University of Uyo, Uyo,Akwa Ibom State, Nigeria; ${ }^{2}$ Department of Zoology, Faculty \\ of Life Science, Ahmadu Bello University, Zaria, Kaduna State, Nigeria \\ Corresponding author email:yaro.ca@uniuyo.edu.ng
}

\section{ABSTRACT}

Background: Schistosomiasis is a Neglected Tropical Disease (NTD) that constitutes a public health problem in Sub-Saharan Africa (SSA), including Nigeria. There is need for updated information on the extent of the disease burden at community level to facilitate effective prioritization and monitoring of the disease.

Methods: A cross-sectional study was conducted among school-aged children in Obudu Local Government Area (LGA), one of the 18 LGAs in Cross River State, Southern Nigeria. Seven schools from seven communities were randomly selected for this study. A total of I,II 3 urine samples obtained from school-aged children were screened for Schistosoma haematobium (S. haematobium) eggs using standard parasitological method of diagnosis. Proteinuria and hematuria were evaluated using reagent test strips.

Results: In this study, I53 (I3.7\%) children were infected with S. haematobium. More males (86 or I4.7\%) were infected than females (67 or $12.7 \%$ ); the differences were not statistically significant. The overall geometric mean intensity of infection was $13.3 \mathrm{eggs} / 10 \mathrm{ml}$ of urine. Females (I3.69 eggs//0ml of urine) had the highest intensity of infection than males $(12.91$ eggs $/ 10 \mathrm{ml}$ of urine). Prevalence of hematuria was $152(13.7 \%)(95 \%$ C.I. $=10.649-18.75 \mathrm{I} \%)$ while the prevalence of proteinuria was $172(15.5 \%)(95 \%$ C.I. $=5.162-38.7 \mathrm{I} 2 \%)$. Prevalence of infection significantly $(\mathrm{p}<0.00 \mathrm{I})$ varied among the schools from $7.8 \%$ to $28.9 \%$. Children aged $5-9$ years old had the highest prevalence of infection 46 (I7.1\%). The prevalence of urogenital schistosomiasis was $28.9 \%, 20.5 \%$ and I $3.2 \%$, respectively, among Betukwel, Ibong, and Ohong communities.

Conclusion and Global Health Implications: Urinary schistosomiasis is still endemic in Obudu, Southern Nigeria but with decreased prevalence. Public health mitigation efforts such as mass chemotherapy, provision of safe water supply and sanitation facilities are recommended. Furthermore, health education should be encouraged within schools and communities.

Key words: • Schistosoma haematobium • Communities • Schools • Neglected tropical diseases $•$ School-aged children $\bullet$ Parasitology $\bullet$ Chemotherapy $\bullet$ Proteinuria $\bullet$ Hematuria $\bullet$ Obudu $•$ Cross River State $・$ Nigeria.

Copyright () 2021 Opara, et al. Published by Global Health and Education Projects, Inc. This is an open-access article distributed under the terms of the Creative Commons Attribution License CC BY 4.0. 


\section{Introduction}

\section{I. Background of the Study}

Urogenital schistosomiasis caused by infection with Schistosoma haematobium (S. haematobium) is widespread and causes morbidity on the African continent.' The World Health Organization (WHO) regards the disease as a Neglected Tropical Disease (NTD) with an estimated 732 million persons being vulnerable to infection worldwide in renowned transmission areas. $^{2}$ However, $85 \%$ of the cases reported annually occur in sub-Saharan Africa (SSA) and over 150,000 deaths are attributable to chronic infection with S. haematobium within regions. ${ }^{3}$ Within SSA, Nigeria has the highest prevalence of human schistosomiasis $^{5}$ with about 29 million infected people. ${ }^{4}$ Other SSA countries such as Kenya ${ }^{6}$ and Ethiopia $^{7}$ estimate that 6 million and over 5 million people are infected with 15 million and 37 million people at risk of infection, respectively.

Humans are infected with this disease when they come in contact with water bodies infested with skin penetrating cercariae. Adult S. haematobium inhabit the venules surrounding organs of the pelvis where they lay between 20 and 200 eggs daily. ${ }^{2}$ During infection, the parasites deposit terminal spine eggs which clog the venous plexus, impeding blood flow. ${ }^{8}$ The eggs of S. haematobium provoke granulomatous inflammation, ulceration and pseudopolyposis of the vesical and ureteral walls. Hematuria is a very common sign of infection but other signs include dysuria, pollakisuria and proteinuria while the mortality caused by schistosomiasis is very low, subtle and indirect morbidities such as fatigue, physical or cognitive impairment are common in children. ${ }^{9}$

In Nigeria, urogenital schistosomiasis is widespread in both rural and urban communities. ${ }^{10,11}$ and the national policy on schistosomiasis control adopted praziquantel as the main drug of choice in the control strategy aimed at reducing morbidity. Dishearteningly, not much progress has been made in the control of urogenital schistosomiasis in the country. Presumably, the disease is more endemic in poor rural communities especially places where fishing and agricultural activities are dominant. There is a high level of the risk of becoming infected as a result of low literacy level, poverty, sub-standard hygiene and inadequate public infrastructure. ${ }^{12}$

Prior studies have reported the endemicity of urinary schistosomiasis in Southern Nigeria ${ }^{13,14}$ and specifically in Obudu. ${ }^{15}$ However, there is paucity of current scientific information on the endemicity of urinary schistosomiasis in many parts of the country especially in the rural areas where the highrisk population are school aged children. Therefore, there is need to provide updated information on the status of urinary schistosomiasis in Southern Nigeria. In addition, previous studies ${ }^{10,15,16}$ on urinary schistosomiasis from this region obtained their samples from one or two communities, but this study increased the geographical coverage to seven communities to provide larger and adequate information on the disease.

\section{I.2. Objective of the Study}

Despite considerable efforts to scale-up treatment activities in all states of Nigeria, coverage still remains poor in most rural and hard to reach communities. This study was designed with the aim of providing updated information on the extent of disease burden among primary school children of rural, communities at risk in Obudu Local Government Area (LGA), Cross River State, Nigeria. It is hoped that the result from this study will add to the existing baseline data on the endemicity of this disease in the country.

\section{Methods}

\section{I. Study Area}

This cross-sectional study was carried out in seven purposively selected communities' in Obudu LGA. Obudu LGA is one out of the 18 LGAs of Cross River State, Nigeria with a population of 215,800 people in 2016. In each of the selected community, a simple random sampling was used to select the school using the lottery method. The communities are;Udigie (Lat. 6.6667 $\mathrm{N}$, Long. 9.1679 ${ }^{\circ} \mathrm{E}$ ); Utugwang (Lat.5.6208 ${ }^{\circ} \mathrm{N}$, Long. 9.0336 ${ }^{\circ} \mathrm{E}$ ); lbong (Lat. 6.5794 ${ }^{\circ} \mathrm{N}$, Long. 9.1273 ${ }^{\circ} \mathrm{E}$ ); Ukwortong (Lat. $6.5942^{\circ} \mathrm{N}$, Long. 9.0721 $\left.{ }^{\circ} \mathrm{E}\right)$; Betukwel (Lat. 6.6054 ${ }^{\circ} \mathrm{N}$, Long. 9.1060 ${ }^{\circ} \mathrm{E}$ ); Ugboro (Lat. 6.662 $1^{\circ} \mathrm{N}$, Long. 8.8419 ${ }^{\circ} \mathrm{E}$ ); and Ohong (Lat. $6.5963^{\circ} \mathrm{N}$, Long. $9.1172^{\circ} \mathrm{E}$ ). Cross River state is 
situated within the tropical rainforest belt of Nigeria. It lies within latitudes $4.4500^{\circ} \mathrm{N}$ to $5.5333^{\circ} \mathrm{N}$ and longitude $7.8333^{\circ} \mathrm{E}$ and $9.4666^{\circ} \mathrm{E}$. The coastal area has an annual rainfall of about $350 \mathrm{~mm}$ while rainfall in the hinterland is between 120 and 200 $\mathrm{mm}$ annually with maximum precipitation occurring from July to September. Most of the communities depend on streams, rivers, rapids and shallow wells as their domestic water supply. These water bodies are frequently visited for water contact activities like bathing, swimming, washing and other domestic activities. Agriculture especially swamprice cultivation, cocoyam cultivation and fishing are the major occupations of the inhabitants of these communities.

\subsection{Study Design and Population}

A school based cross-sectional study was conducted between June to December 2016. School- aged children aged 4-14 years were enrolled from 7 primary schools in each of the seven communities. Participants were selected by first stratifying the children according to the different classes (I-6) and then randomly selecting equal proportion of children in the different grades. This was done for all the seven schools.

\subsection{Exclusion Criteria}

Primary school children given chemotherapy for schistosomiasis during the national deworming program by $\mathrm{WHO}$ through the state ministry of health three weeks prior to and during the data collection at home were excluded during the study. The deworming status was verified while seeking their consent to participate in the study.

\subsection{Sample Size Determination}

This was estimated using the sample size formula ${ }^{17}$ as calculated below:

$$
n=\frac{Z^{2} \times p(l-p)}{e^{2}}
$$

$Z=1.96(95 \%)$

$\mathrm{P}=$ prevalence of urogenital schistosomiasis $=50 \%$

$\mathrm{e}=$ error rate $0.05(5 \%)$

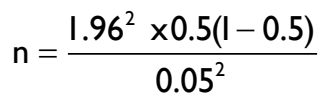

$\mathrm{n} \sim=384+20 \%$ non-respondent value $=384+$ $77=46 \mathrm{I}$.

The minimum sample size is $46 \mathrm{I}$ pupils.

A total of $1 \mathrm{II} 3$ individuals, comprising of 587 males and 526 females were selected randomly from the surveyed schools.

\subsection{Ethical Consideration}

This study was performed under a protocol that was reviewed and approved by the Research Ethics Committee of Cross River State Ministry of Health (CRSMoH), Calabar. Ethical approval was also obtained from the Local Government Education Authority Consent was verbally obtained from parents and Head teachers of children of the various schools. The village heads and opinion leaders were briefed on the objectives and purpose of the study. The respondents were interviewed in their classrooms with the assistance of their teachers.

\subsection{Sample Collection}

Each consenting child was provided with a $50 \mathrm{ml}$ capacity autoclaved wide-mouthed screw capped container for collection of a mid-day urine sample. Samples were obtained between 10.00 hours and 14.00 hours, when egg excretion is usually maximal. ${ }^{10}$ Samples with visible hematuria were noted. The specimens were approximately labelled with identification numbers and placed in cold box with 16 packs immediately after collection. They were processed I-2 hours from collection. In situations where delay in transportation of specimen to laboratory was inevitable, $0.2 \mathrm{ml}$ of $37 \%$ formalin was added to urine sample as a preservative.

\subsection{Parasitological Examination}

Sedimentation quantitative technique was employed for the detection of S. haematobium eggs in the urine samples as previously described. ${ }^{18}$ Briefly, $10 \mathrm{ml}$ of each thoroughly mixed urine sample was put in a centrifuge tube. The centrifuge was spun for 
5 minutes at $1500 \mathrm{rpm}$. The supernatant was decanted leaving about $0.5 \mathrm{ml}$ of the fluid with the sediment at the bottom of the tube undisturbed. The remaining fluid and sediment were mixed, then a drop of the mixture was transferred to a microscope slide and covered with a cover slip. The slide was meticulously examined for $\mathrm{S}$. haematobium using $\mathrm{xIO}$ objectives. The eggs seen were counted and the intensity of infection per $10 \mathrm{ml}$ of urine accordingly determined. The intensity of S. haematobium was classified as light infection: I-49 egg/ I $0 \mathrm{ml}$ of urine; and heavy infection: $\geq 50 \mathrm{egg} / 10 \mathrm{ml}$ of urine. ${ }^{19}$

\subsection{Examination of Urine for Hematuria and Proteinuria}

Within 2 hours of urine sample collection, hematuria and proteinuria were detected in the field using dipsticks (Medi-Test Combi-9 manufactured by Machery-Hagel Duren, Germany). The reagent end of the test strip was dipped into fresh, well-mixed uncentrifuged urine for 40 seconds. Upon removal, the test area was compared with a standard color as described by the manufacturer. ${ }^{10}$

\subsection{Statistical Analysis}

Data obtained were entered into Microsoft Excel for Windows, version 2013 (Microsoft Corporation, Redmond, Washington, USA). Descriptive statistics and chi-square tests were performed on data at $95 \%$ Confidence Interval (C.I.) and Level of significance (P) set at $p \leq 0.05$ using the Statistical Package for Social Sciences (SPSS) for Windows, version 20.0 (SPSS Inc. Chicago, IL, USA).

\section{Results}

\section{I. Demographic Characteristics}

A total of I, II 3 school children were examined for urogenital schistosomiasis comprising of 587 males $(52.7 \%)$ and 526 females (47.3\%). The age group of I0-1 4 years were the highest respondents with 830 (74.6\%) children followed by $5-9$ year-olds with 269 (24.6\%) (Table I).

\subsection{Prevalence of Urogenital Schistosomiasis}

Among the I,II3 school children examined, I53 were observed shedding eggs of S. haematobium in their urine giving an overall prevalence of $13.7 \%$ (95\% C.I. $=6.207-21.193 \%)$. Prevalence in schools ranged from $7.8 \%$ to $28.9 \%$ and $42.9 \%$ (3/7) of the schools had infection prevalence of $>10 \%$. Significant difference $(p<0.00 \mathrm{I})$ was observed in the prevalence of the parasites among the selected schools (Table 2). Males (86 (I4.7\%) (95\% C.I. = 6.87I - 22.329\%): were more infected than females (67 (12.7\%) $(95 \%$ C.I. $=4.442-20.6 I 5 \%))$. There was no significant difference $(p=0.355)$ in the prevalence between male and female pupils (Table 2).

Children age 5 to 9 years old (46 pupils or $17.1 \%$ ) had the highest prevalence compared to those in the age groups of $15-19$ years (16.7\%), 10- 14 years (I2.7\%) and $0-4$ years (I2.5\%) (Fig. I). There was no significant difference in prevalence among the age groups $\left(\chi^{2}=3.446, d f=3, p=0.328\right)$ (Table 3$)$.

\subsection{Prevalence of Hematuria and Proteinuria}

Hematuria is the presence of blood in urine while proteinuria is the presence of protein in urine. The total prevalence of hematuria was I52 (13.7\%) $(95 \%$ C.I. $=10.649-18.751)$. The $5-9$ years age group had the highest hematuria rate of 46 (17.1\%)

Table I: demographic characteristics of the study population

\begin{tabular}{|c|c|}
\hline Characters & Total (\%) \\
\hline \multicolumn{2}{|l|}{ Sex } \\
\hline Male & $587(52.7)$ \\
\hline Female & $526(47.3)$ \\
\hline \multicolumn{2}{|l|}{ Age group (Years) } \\
\hline $0-4$ & $8(0.7)$ \\
\hline $5-9$ & $269(24.2)$ \\
\hline $10-14$ & $830(74.6)$ \\
\hline $15-19$ & $6(0.5)$ \\
\hline \multicolumn{2}{|l|}{ Communities/primary school } \\
\hline Lishegie Kushu Primary School, Udigie & $150(13.5)$ \\
\hline Universal Primary School, Utugwang & $152(13.7)$ \\
\hline Saint Pius Primary School, lbong & $166(14.9)$ \\
\hline Saint John Primary School, Ukwortong & $168(15.1)$ \\
\hline Saint Joseph Primary School, Betukwel & $159(14.3)$ \\
\hline Community Primary Sch.ool Ugboro & $167(15.0)$ \\
\hline Bediagin Primary School, Ohong & $151(13.6)$ \\
\hline Total & 1113 \\
\hline
\end{tabular}


Table 2: Prevalence of urogenital schistosomiasis by sex in each school in the study area

\begin{tabular}{|c|c|c|c|c|c|c|}
\hline \multirow[t]{2}{*}{ Schools } & \multicolumn{2}{|c|}{ Male } & \multicolumn{2}{|c|}{ Female } & \multicolumn{2}{|c|}{ Total } \\
\hline & $\begin{array}{l}\text { Number } \\
\text { Examined }\end{array}$ & $\begin{array}{c}\text { Number } \\
\text { Infected (\%) }\end{array}$ & $\begin{array}{l}\text { Number } \\
\text { Examined }\end{array}$ & $\begin{array}{c}\text { Number } \\
\text { Infected (\%) }\end{array}$ & $\begin{array}{l}\text { Number } \\
\text { Examined }\end{array}$ & $\begin{array}{c}\text { Number } \\
\text { Infected (\%) }\end{array}$ \\
\hline Lishegie Kushu Primary School, Udigie & 82 & $8(9.8)$ & 68 & $4(5.9)$ & 150 & $12(8.0)$ \\
\hline Universal Primary School, Utugwang & 84 & $9(10.7)$ & 68 & $4(5.9)$ & 152 & $13(8.6)$ \\
\hline Saint Pius Primary School, Ibong & 85 & $19(22.4)$ & 81 & $15(18.5)$ & 166 & $34(20.5)$ \\
\hline Saint John Primary School, Ukwortong & 83 & $4(4.8)$ & 85 & $\mathrm{II}(12.9)$ & 168 & $15(8.9)$ \\
\hline Saint Joseph Primary School, Betukwel & 84 & $24(28.6)$ & 75 & $22(29.3)$ & 159 & $46(28.9)$ \\
\hline Community Primary School Ugboro & 83 & $8(9.6)$ & 84 & $5(6.0)$ & 167 & $13(7.8)$ \\
\hline Bediagin Primary School, Ohong & 86 & $14(16.3)$ & 65 & $6(9.2)$ & 151 & $20(13.2)$ \\
\hline Total & 587 & $86(14.7)$ & 526 & $67(12.7)$ & 1113 & $153(13.7)$ \\
\hline$\chi^{2}$ & \multicolumn{2}{|c|}{27.928} & \multicolumn{2}{|c|}{30.971} & \multicolumn{2}{|c|}{53.233} \\
\hline Df & \multicolumn{2}{|c|}{6} & \multicolumn{2}{|c|}{6} & \multicolumn{2}{|c|}{6} \\
\hline $\mathrm{P}$ value & \multicolumn{2}{|c|}{$<0.001 *$} & \multicolumn{2}{|c|}{$<0.00 I^{*}$} & \multicolumn{2}{|c|}{$<0.001 *$} \\
\hline $95 \%$ C.I. & \multicolumn{2}{|c|}{$6.87 I-22.329$} & \multicolumn{2}{|c|}{$4.442-20.615$} & \multicolumn{2}{|c|}{$6.207-21.193$} \\
\hline
\end{tabular}

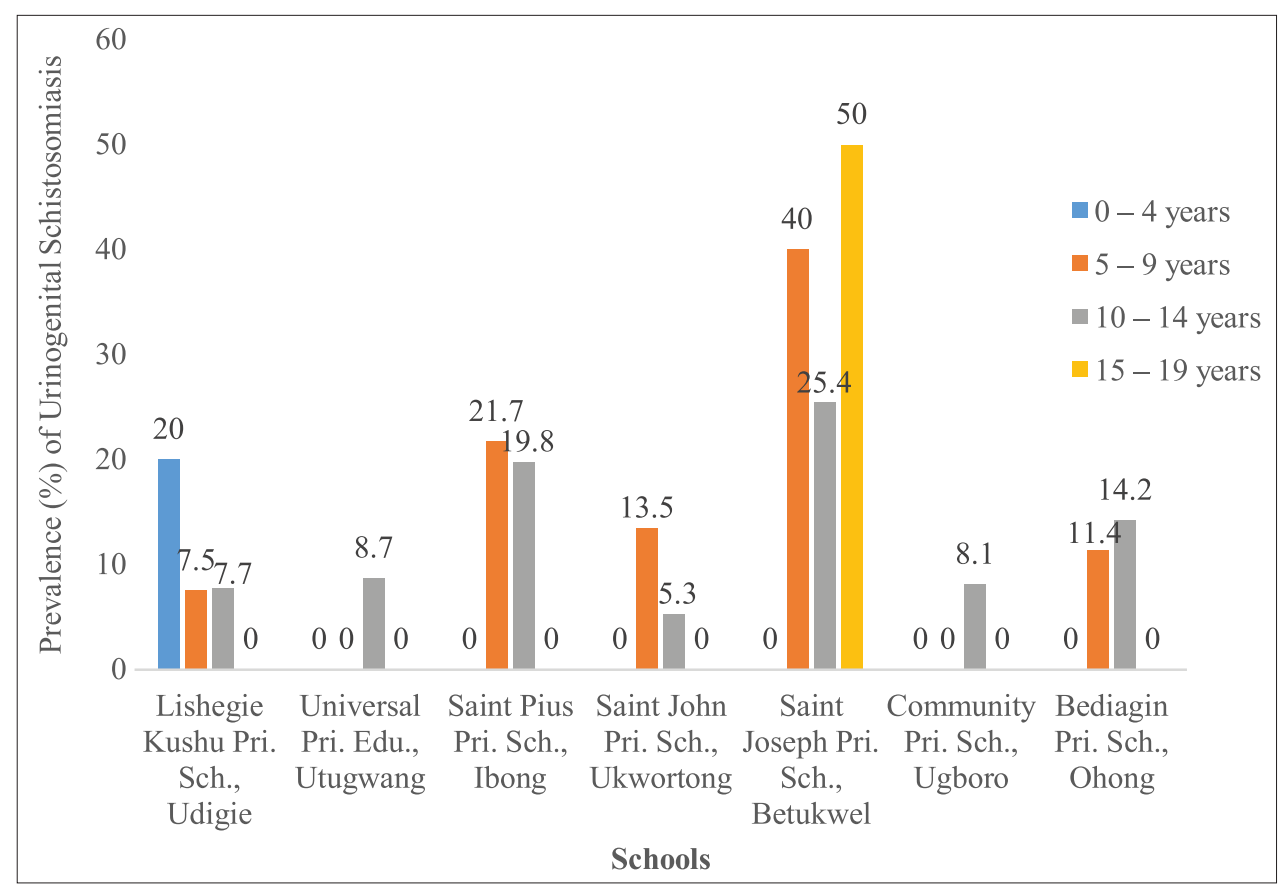

Figure I: Prevalence of Urogenital Schistosomiasis in Relation to Age and School in the Study Area

(Fig. 2). The prevalence of proteinuria was 172 $(I 5.5 \%)(95 \%$ C.I. $=5.102-38.7$ I2.), with the I519 age group having the highest prevalence of 2 (33.3\%) (Fig. 3). Proteinuria was not observed in the age group of $0-4$ years, significant difference $\left(\chi^{2}=7.818, \mathrm{df}=3, \mathrm{p}=0.050\right)$ was observed in the prevalence of proteinuria among the age groups (Table 3). 
Table 3: prevalence of urogenital schistosomiasis, proteinuria and hematuria in relation to age in the study area

\begin{tabular}{|c|c|c|c|c|}
\hline Age group (Years) & $\begin{array}{l}\text { Number } \\
\text { examined }\end{array}$ & $\begin{array}{c}\text { Number } \\
\text { infected (\%) }\end{array}$ & $\begin{array}{c}\text { Number with } \\
\text { proteinuria (\%) }\end{array}$ & $\begin{array}{l}\text { Number with } \\
\text { hematuria (\%) }\end{array}$ \\
\hline $0-4$ & 8 & $\mathrm{I}(12.5)$ & $0(0.0)$ & $I(12.5)$ \\
\hline $5-9$ & 269 & $46(17.1)$ & $53(19.7)$ & $46(17.1)$ \\
\hline $10-14$ & 830 & $105(12.7)$ & $117(14.1)$ & $104(12.5)$ \\
\hline $15-19$ & 6 & $\mathrm{I}(\mathrm{I} 6.7)$ & $2(33.3)$ & $\mathrm{I}(16.7)$ \\
\hline Total & 1113 & $153(13.7)$ & $172(15.5)$ & $153(13.7)$ \\
\hline$\chi^{2}$ & & 3.446 & 7.818 & 3.654 \\
\hline Df & & 3 & 3 & 3 \\
\hline$P$ value & & $0.328 \mathrm{~ns}$ & $0.050 *$ & $0.30 \mathrm{Ins}$ \\
\hline 95\% C.I. & & $10.789-|8.7| \mid$ & $5.162-38.712$ & $|0.649-| 8.75 \mid$ \\
\hline
\end{tabular}

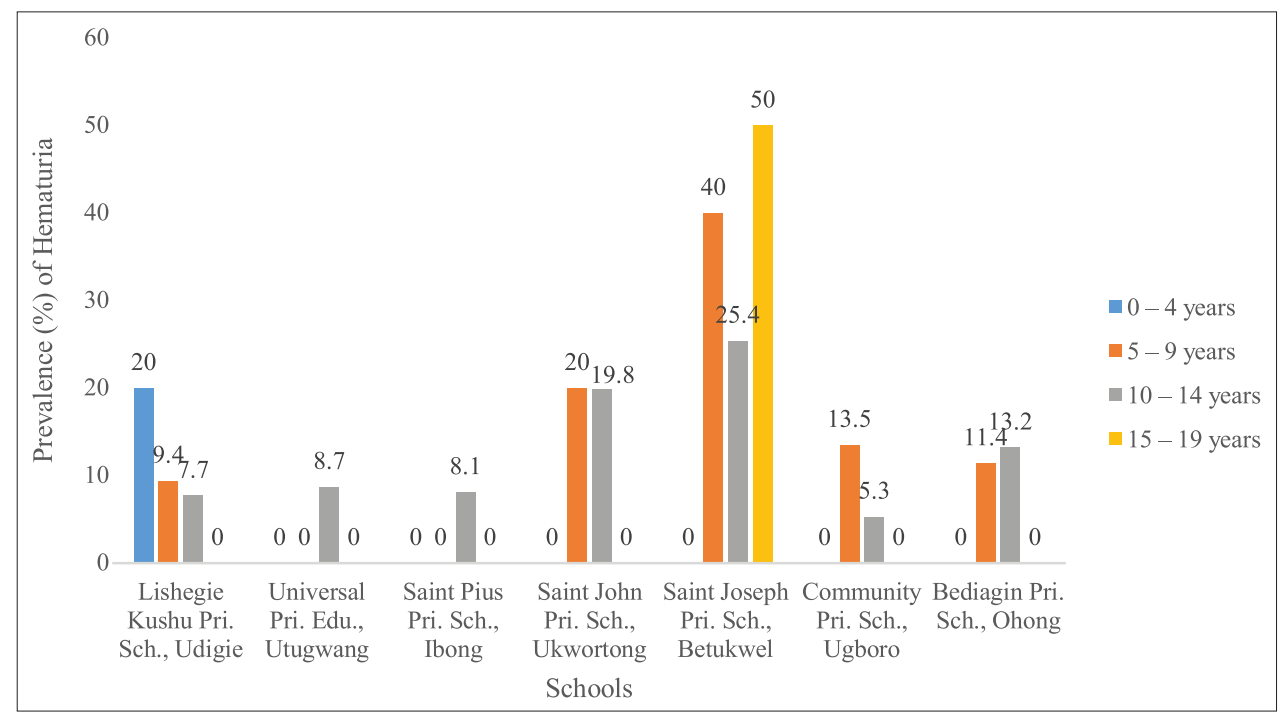

Figure 2: Prevalence of Hematuria in Relation to Age and School in the Study Area

\subsection{Mean Intensity}

Mean intensity represents the arithmetic mean of the number of individual S. haematobium parasites per infected host in a sample. The overall ova intensity (eggs/10ml of urine) among the infected children was $13.30 \mathrm{eggs} / 10 \mathrm{ml}$ urine (range $2.0 \mathrm{eggs} / 10 \mathrm{ml}$ urine to 63 eggs $/ 10 \mathrm{ml}$ urine). Females had a higher intensity of 13.69 eggs $/ 10 \mathrm{ml}$ urine than males of 12.9 l eggs $/ 10 \mathrm{ml}$ urine $(\mathrm{pP}=0.236)$. Community-level intensity varied among schools from 10.0 eggs $/ 10 \mathrm{ml}$ urine in lbong to $26.2 \mathrm{eggs} / \mathrm{I} 0 \mathrm{ml}$ urine in Ohong, while the age group 15-19 years had the highest intensity (34.0 eggs/ $/ 0 \mathrm{ml}$ of urine) when compared to other age groups (Table 4).

\section{Discussion}

This study has reconfirmed the endemicity of urinary schistosomiasis in Obudu, Cross River State, Nigeria. Also, the study revealed decreased prevalence from 91.0\% previously in Obudu ${ }^{15}$ to $13.7 \%$ and geometric mean intensity of 86.84 eggs $/ 10 \mathrm{ml}$ to $13.3 \mathrm{eggs} / \mathrm{IOml}$ of urine. This study provides an updated information on the decreased burden of urinary schistosomiasis in Obudu communities, Southern Nigeria. 


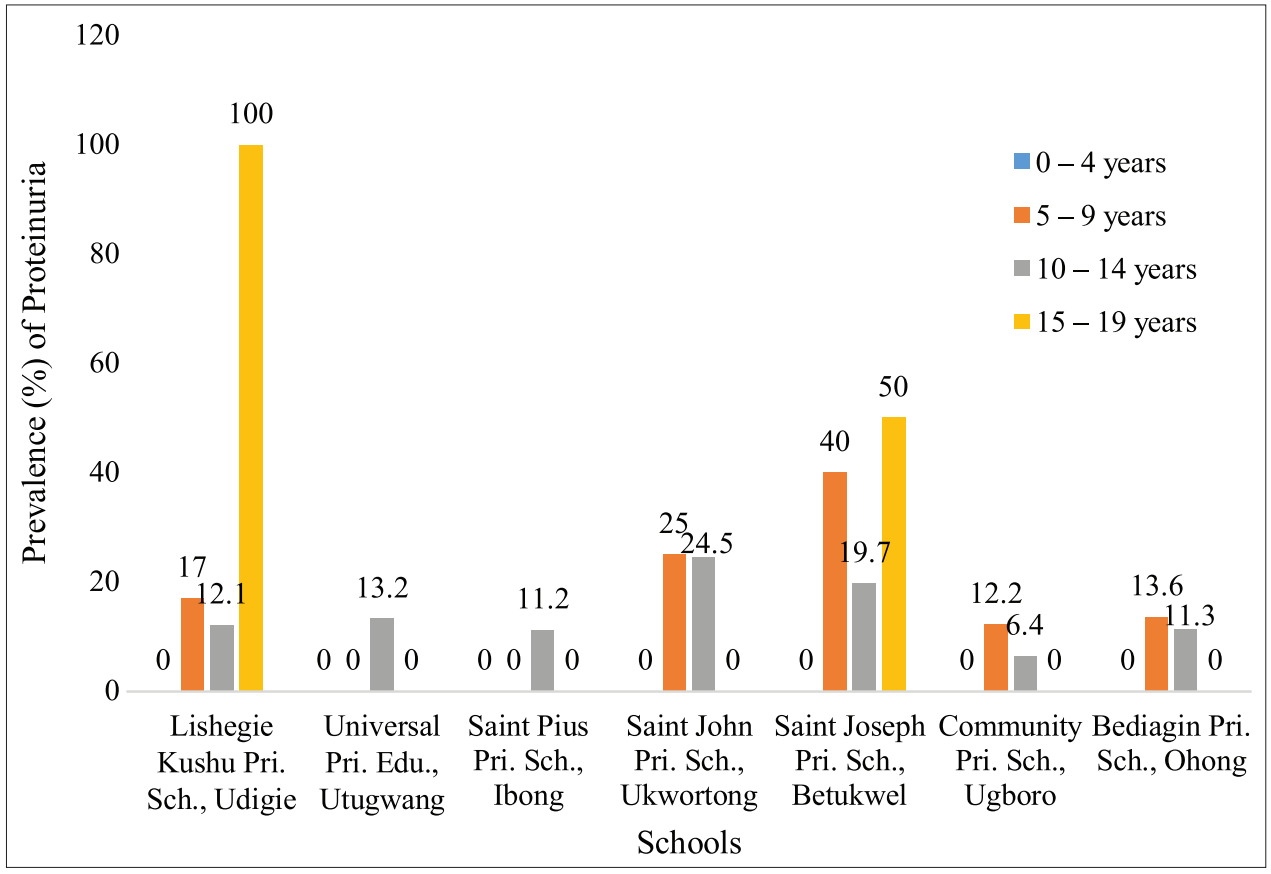

Figure 3: Prevalence of Proteinuria in Relation to Age and School in the Study Area

Table 4: Geometric mean intensity of schistosomiasis infection by age and community in the urine of infected children in obudu L.G.A.

\begin{tabular}{|c|c|c|c|c|c|}
\hline \multirow[t]{2}{*}{ Schools } & \multicolumn{4}{|c|}{ Geometric mean intensity } & \multirow[t]{2}{*}{ Total } \\
\hline & $0-4$ years & $5-9$ years & $10-14$ years & $15-19$ years & \\
\hline Lishegie Kushu Primary School, Udigie & 25.0 & 11.6 & 12.9 & - & 13.2 \\
\hline Universal Primary School, Utugwang & - & - & 10.6 & - & 10.6 \\
\hline Saint Pius Primary School, Ibong & - & 9.62 & 10.24 & - & 10.0 \\
\hline Saint John Primary School, Ukwortong & - & 20.9 & 31.6 & - & 24.0 \\
\hline Saint Joseph Primary School, Betukwel & - & 16.0 & 10.3 & 34.0 & 12.11 \\
\hline Community Primary School Ugboro & - & - & 18.4 & - & 8.4 \\
\hline Bediagin Primary School, Ohong & - & 16.2 & 30.7 & - & 26.2 \\
\hline Total & 25.0 & 14.3 & 12.6 & 34.0 & 13.3 \\
\hline
\end{tabular}

Comparison between male and female: $\chi^{2}=0.856, \mathrm{df}=1, \mathrm{p}$ Value $=0.355$

Understanding the geographical distribution of a disease is fundamental prior to initiation of control program based on mass drug distribution. This is to determine where to target mass treatment. The overall prevalence of $13.7 \%$ reported in this study is similar to $19.8 \%$ and $10.2 \%$ reported other parts of Cross River State. ${ }^{10,20}$ A study in Malawi ${ }^{21}$ obtained a similar prevalence of $10.4 \%$ among school children. However, higher prevalence rates of $32 \%$,
40.1\%, and 4I.1\% were obtained by prior studies among school children. ${ }^{22-24}$ According to WHO guidelines on preventive chemotherapy in human helminthiasis, school children living in communities where the prevalence of infection with the parasites lies between $10 \%$ and $50 \%$ require mass drug administration with praziquantel every two years to control schistosomiasis morbidity. ${ }^{25}$ Prevalence was observed to vary between the schools in different 
communities (7.8\% to $28.9 \%$ ), demonstrating the focal distribution characteristic of schistosomiasis. The socioeconomic status and the local environmental conditions of the communities where the schools are located may be responsible for these variations. In addition, the different degrees of exposures of the children to infested bodies of water might also have accounted for the variation in prevalence. In Nigeria, rural communities' access to potable water is limited or non-existent. Consequently, the inhabitants of these communities depend on natural bodies of water such as lakes, streams, ponds and rivers for their daily domestic chores. It is plausible that these water bodies may have been infested with schistosome parasites thereby serving as veritable source of infection.

A higher prevalence of infection was observed among males than females with no significant difference. This is indicative that both sexes are equally exposed to infection through risk factors such as swimming, playing, washing and fetching water in infested bodies. This finding is consistent with prior studies. ${ }^{10,26-28}$ Furthermore, the study observed that females were not restricted in carrying out activities that may expose them to infection based either on cultural or religious grounds.

The age-related prevalence may be attributed to the frequency and duration of contact with the water and the nature of the water-contact activities at the index site. ${ }^{29}$ In this study, the high prevalence observed among the 5-9 year-old age group may be due to the adventurous tendencies of this group that expose them to various activities that serve as risk factors for $S$. haematobium infection. This finding is consistent with documented reports. ${ }^{22,24,30}$ This, however, contrasts with other conducted elsewhere ${ }^{31-32}$ which reported a higher prevalence in among the age group II - I 3 years. Our study showed that there as an increasing trend of infection among children from 5 years to 14 years with a decline after 15 years. This could be attributed to the fact that as the children grow older, they become more aware and begin to follow basic rules of hygiene limiting their contact with infested water bodies. ${ }^{24}$

This study showed lower mean intensity of urogenital schistosomiasis (I3.3 eggs/ / $0 \mathrm{ml}$ of urine) when compared to 149 eggs/ I $0 \mathrm{ml}$ urine reported by Babatunde et al. ${ }^{7}$ Our finding is consistent with I4.9 eggs $/ 10 \mathrm{ml}$ documented in similar studies. ${ }^{33,34}$ The difference in intensity of infection could be associated with differences in seasonality in transmission and types of water contact among study participants. ${ }^{35,36}$

Proteinuria and hematuria often associated with schistosomiasis have often been regarded as important markers for diagnosing the disease..$^{37,38}$ The prevalence rates of $13.7 \%$ and $15.5 \%$ for hematuria and proteinuria, respectively, in the study schools were quite significant; these rates may potentially change over time with their attendant pathological damages, if not treated early.

Poverty, ignorance, poor living conditions, inadequate sanitation and water supplies as well as deplorable personal and environmental hygiene characteristics of many rural communities in Nigeria are important factors that contribute to increased transmission of schistosomiasis. ${ }^{39}$ These factors may singly or collectively contributed to the moderate prevalence observed in this study.

Although urogenital schistosomiasis is perceived by the residents in our study communities as a public health problem, knowledge about the parasite causing the disease and the vector is poor. Members of the communities were aware of the fact that some of their children pass bloody urine referred to as "betiela anu" or "giabetie la anu" the local name for urogenital schistosomiasis. They were willing to support and participate in any community-based control program.

\section{I. Limitations}

This study has some limitations. The geographic distribution of schistosomiasis species is closely dependent on the presence of appropriate freshwater snails (Bulinus and Biomphalaria) that serve as obligatory molluscan host. In this study a detailed malacological studies of the community streams was not carried out. However, on-thespot check of the streams revealed the presence of Bulinus snail vectors of Schistosoma haematobium. Additionally, cases of high-risk infection were not recorded, however, those of moderate to low-risk infection were quite high and could transform to 
high-risk if they remain untreated. Our study results should therefore be interpreted within the context of these limitations.

\subsection{Recommendations for Further Studies}

Given the presence of urogenital schistosomiasis in Obudu LGA, there is need to initiate control programs so as to arrest the progression of the disease to an alarming rate. The national schistosomiasis control program should consider targeted treatment every two years in schools and surrounding communities with prevalence of between $10 \%$ but less than $50 \%$. In addition, potable water should be provided in the schools and communities to reduce human-vector contact. Adequate snail vector control program should also be implemented to check intermediate snail host population expansion in the study area.

\section{Conclusion and Global Health Implications}

This study established the presence of urogenital schistosomiasis in Obudu LGA. It has also enriched the baseline studies of the disease in the state and findings would be relevant for other parts of the country. The state Ministry of Health should consider public health intervention programs aimed at reducing the burden of urogenital schistosomiasis in these communities as well as the entire state.

\section{Compliance with Ethical Standards}

Conflicts of Interest: The authors declare that they have no competing interest. Funding/Support: There was no funding for this study. Ethics Approval: This study was performed under a protocol that was reviewed and approved by the Research Ethics Committee of Cross River State Ministry of Health (CRSMoH), Calabar. Acknowledgements: We gratefully acknowledge the Chief Medical Director, Cross River State Ministry of Health (CRSMoH), Calabar and the Education Secretary, Obudu Local Government Education Authority for the permission to carry out the study in the state. The Village Heads of each of the community are appreciated for their cooperation. Tremendous assistance was received from the Head Teacher, Teachers and Students of the respective Schools. Disclaimer: None

\section{Key Messages}

The prevalence of urogenital schistosomiasis in Obudu LGA is $13.7 \%$.

- Targeted treatment of school-aged children should be done every two years to reduce the transmission as recommended by the World Health Organization (WHO).

- Improvement in the water, sanitation and hygiene infrastructures as well as health education should be implemented across the rural communities included in this study.

\section{References}

I. Mbabazi PS, Andan O, Fitzgerald DW, Chitsulo L, Engels D. Examining the Relationship between Urogenital Schistosomiasis and HIV Infection. PLOS Negl Trop Dis. 20II;5(I2):el396. https://doi.org/I0.I37I/journal. pntd.0001396

2. Centers for Disease Control and Prevention.Schistosomiasis - Biology. https://www.cdc.gov/parasites/schistosomiasis/ index.html.Accessed December 27, 2019.

3. Van der Werf MJ, de Vlas SJ, Brooker S, Looman CW, Nagelkerke NJ, Habbema JDF, Engels D. Quantification of clinical morbidity associated with schistosome infection in sub-Saharan Africa.Acta Trop. 2003;86(2-3):125-139. https:// doi.org/I0.1016/s0001-706x(03)00029-9

4. Hotez PJ, Kamath A. Neglected tropical diseases in subSaharan Africa: review of their prevalence, distribution and disease burden. PLOS Neg/Trop Dis. 2009;3:e4I2. https://doi. org//0.137//journal.pntd.00004/2

5. Hotez PJ, Asojo OA, Adesina AM. Nigeria. "Ground Zero" for the High Prevalence Neglected Tropical Diseases. PLOS Negl Trop Dis. 2012;6(7):el600. https://doi.org//0.137// journal.pntd.0001600

6. Hotez PJ, Kamath A. Neglected Tropical Diseases in SubSaharan Africa: Review of Their Prevalence, Distribution, and Disease Burden. PLOS Negl Trop Dis. 2009;3(8):e4I2. https://doi.org//0.137//journal.pntd.00004/2

7. Deribe K, Meribo K, Gebre T, Hailu A, Ali A, Aseffa A and Davey, G. The burden of neglected tropical diseases in Ethiopia, and opportunities for integrated control and elimination. Parasit Vectors. 2012;5:240. https://doi. org/10.1 I86/1756-3305-5-240

8. Babatunde TA, Asaolu SO, Sowemimo OA. Urinary schistosomiasis among pre-school and school aged children in two peri-urban communities in Southwest Nigeria. J Parasitol Vector Biol 2013;5(7):96-10I. https://doi. org/I0.5897/JPVB2013.01 I3 
9. Gryseels B, Polman K, Clerinx J, Kestens L. «Human Schistosomiasis». Lancet. 2005;368 (954 I): I I06-I I I8.

10. Opara KN, Udoidung NI, Ukpong IG. Genitourinary schistosomiasis among pre-primary schoolchildren in rural community within the Cross River Basin, Nigeria. J Helminthol. 2007;81:393-397. https://doi.org/10.1017/ S0022I 49X0785352I.

II. Ugbomoiko US, Ofoezie IE, Okoye IC, Heukelbach J. Factors associated with urinary schistosomiasis in two peri-urban communities in south-western Nigeria. Ann Trop Med Parasitol. 20 I0; 104(5): 409-419. https://doi.org/10.1 I 7 9/1364859/0X12743554760469

12. Uneke CJ. Soil transmitted helminth infections and schistosomiasis in school age children in sub-Saharan Africa. Efficacy of chemotherapeutic intervention since World Health Assembly Resolution 200I. Tanzan J Health Res. 2010; I2(I): I-I5. https://doi.org/| 0.43 |4/thrb.v I2il.56366

13. Ejezie GC, Uko IE, Braide El. Schistosomiasis in Cross River State, Nigeria. Prevalence and intensity of infection in Adim - Akamkpa Local Government Area.J Hyg Epidemiol Microbiol Immunol. 1991;35:14I - I47.

14. Inyang-Etoh PC, Ejezie GC, Useh MF, Inyang-Etoh EC. Efficacy of a combination of praziquantel and artesunate in the treatment of urinary schistosomiasis in Nigeria. Trans R Soc Trop Med Hyg. 2009; I03(I):38 - 44. https://doi. org/I0.1016/j.trstmh.2008.08.002

15. Okon OE, Umeche N. Distributors of urinary schistosomiasis among high school students in Otukwang, Obudu, Cross River State of Nigeria. Glob J Med Sci. 2003;2:19-22. https://doi.org//0.43 |4/gjms.v2il. 10090

16. Akpan SS, Dike PC and Mbah M. The Prevalence of Urinary Schistosomiasis among School Children in Nkarasi and Edor Communities in Ikom Local Government Area of Cross River State, Nigeria. Pyrex J Med Med Sci. 20I7;4(I):I-4.

17. Swinscow TDV, Campbell MJ. Statistics at Square. I0th Edition, BMJ Books, London; 2002.

18. Gray DJ, Ross AG, Li YS. Diagnosis and management of schistosomiasis. BMJ. 20II; 342:D2265I. https://doi. org/I0.1 |36/bmj.d265।

19. Cheesbrough M. Parasitological examinations: District Laboratory Practices in Tropical Countries, Part 2. Cambridge: Cambridge University Press, UK; 2010.

20. Adie HA, Okon OE, Arong GA, Braide El, Ekpo UF. Spatial distribution of urinary schistosomiasis in Cross River State, Nigeria using geographical information system and schoolbased questionnaire. Pak J Biol Sci. 20 I 3; I 6(20): I I 66-I I 72. https://doi.org/I0.3923/pjbs.2013.1 I66.1 I72

21. Kapito-Tembo AP, Mwapasa V, Meshnick SR, Samanyika Y, Banda D, Bowie C, Radke S. Prevalence, distribution and risk factors of Schistosoma haematobium infection among school children in Blantyre, Malawi. PLOS Negl Trop Dis.
2009;3:36 I. https://doi.org/I0.137|/journal.pntd.000036 |

22. Salawu AS, Asaolu SO, Sowemimo OA. Co-infection with Schistosoma haematobium and soil transmitted helminths among school-aged children in Saki Oyo state Nigeria. J Public Health Epidemiol. 2014; 6(I2): 4I7-423. https://doi. org/I0.5897/JPHE20I4.0664

23. Campell SJ, Stohard JR, O'Halloran F, Sankey D, Durant T. Urogenital schistosomiasis and soil transmitted helminthiasis STH) in Cameroon: An epidemiological update at Barombi Mbo Barombi Kotto crater Lakes assessing prospects for intensified control intervention. Infect Dis Poverty. 2017;6:49. https://doi.org/10.1/86/ s40249-0I 7-0264-8

24. Njunda AL, Ndizi EN, Assob JCN, Kamga HLF, Kwenti ET. Prevalence and risk factors asssociated with urogenital schistosomiasis among primary school children in Barage, Magba sub division of Cameroon. BMC Public Health. 20I7; 17:618.

25. World Health Organization. Schistosomiasis and soiltransmitted parasite infections: Preliminary estimates of the number of children treated with Albendazole or Mebendazole. Published 2006. https://www.who.int/ schistosomiasis/resources/who_wer8II6/en/. Accessed February 2, 2019.

26. Satayathum SA, Muchiri EM, Ouma JH,Whale CC, King $\mathrm{CH}$. Factors affecting infection or reinfection with Schistosoma haematobium in coastal Kenya: survival analysis during a nine-year, school-based treatment program. Am J Trop Med Hyg. 2006;75(I):83-92.

27. Akinboye DO, Ajisebutu JU, Fawole O, Agbolade OM, Akinboye OM, Amosu AM, Atulomah NO, Awodele O, Oduola O, Owoduni BM, Rebecca SN, Falade M, Emem O. Urinary Schistosomiasis: Water contact frequency and infectivity among secondary school students in Ibadan, Nigeria. Nigerian J Parasitol. 20 I I;32(I): I 29-134.

28. Rudge JW, Stothard JR, Basanez M, Ali FM, Khamis AN, Rellinson D. Micro-epidemiology of urinary schistosomiasis in Zanzibar: local risk factors associated with distribution of infections among school children and relevance for control. Acta Trop. 2008; 105: 45-84. https://doi.org/10.1016/j. actatropica.2007.09.006

29. Udonsi JK. Human community ecology of urinary schistosomiasis in relation to snail vector bionomics in the Igwun River Basin of Nigeria. Trop Med Parasitol. 1990; |4I(2): I3| - I35.

30. Dunah CS, Bristono B. The Prevalence of schistosoma haematobium among Primary school pupils in Mayo Belwa Local Government Area of Adamawa Stale. Nigeria J Parasitol. 2000; 2 I:I5-20.

31. Ingang-Etoh PC, Essien UC,Amama SA, Useh MF.Prevalence of urinary schistosomiasis among school children in Ukwelo-Obudu and Abini communities in Cross River 
State, Nigeria. Port Harcourt Med J. 2009; 3(3). http://dx.doi. org/I0.43 I4/phmedj.v3i3.4525 I

32. Ugochukwu DO, Onwuliri COE, Osuala FOU, Dozie INS, Opara FN, Nweny UC. Endemicity of schistosomiasis in some parts of Anambra State, Nigeria. J Med Lab Diagn. 2013; 4(5): 54-6I. https://doi.org/I0.5897/JMLD20I 3.0072

33. Houmsou RS,Amuta EU, SarTT.Profile of an epidemiological study of urinary schistosomiasis in two local government areas of Benue state, Nigeria. Int J Med Biomed Res. 2012; I(I): 39-48.

34. Senghor B, Diaw OT, Doucoure S, Seye M, Diallo A, Talla I. Impact of Annual Praziquantel Treatment on Urogenital Schistosomiasis in a Seasonal Transmission Focus in Central Senegal. PLOS Neg/ Trop Dis. 2016; 10(3): e0004557. https:// doi.org// 0.137//journal.pntd.0004557.

35. Clement AC, Barnett AG, Nyandindi U, Lwambo NJ, Kihamia CM, Blair L. Age and gender effects in selfreported urinary schistosomiasis in Tanzania. Trop Med Int Health. 2008; 13(5): 7|3-72I. https://doi.org/I0.I I I I/ j.1365-3/56.2008.02048.x

36. Senghor R, Diallo A, Sylla SN, Doucoure S, Ndiath MO, Gaaye I, Djuikwo-Teukeng F, Cheikh TB, Sokhna C. Prevalence and intensity of urinary schistosomiasis among school children in the district of Njakhar, region of fatick, Senegal. Parasit Vector. 2014; 7:5. https://dx.doi. org// 0.1 I 86\%2FI756-3305-7-5

37. Robinson E, Picon D, Sturrock HJ, Sabasio A, Lado M, Kolaczinski J, Brooker S. The performance of hematuria reagent strips for the rapid mapping of urinary schistosomiasis: field experience from Southern Sudan. Trop Med Int Health. 2009; I4(I2): I484-I487. https://doi. org/I 0. I I I I/j. I 365-3 I56.2009.02407.x

38. Fatiregun AA, Osungbade KO, Olumide EA. Diagnostic performance of screening methods for urogenital schistosomiasis in a school-based control programme in Ibadan, Nigeria. J Commun Med Primary Health Care. 2005; 17:24-27.

39. World Health Organization. Report of the WHO Informal Consultation on Schistosomiasis Control Geneva. Published 1998. https://www.who.int/schistosomiasis/ resources/who_cds_cpc_sip_99.2/en/. Accessed February $2,2019$.

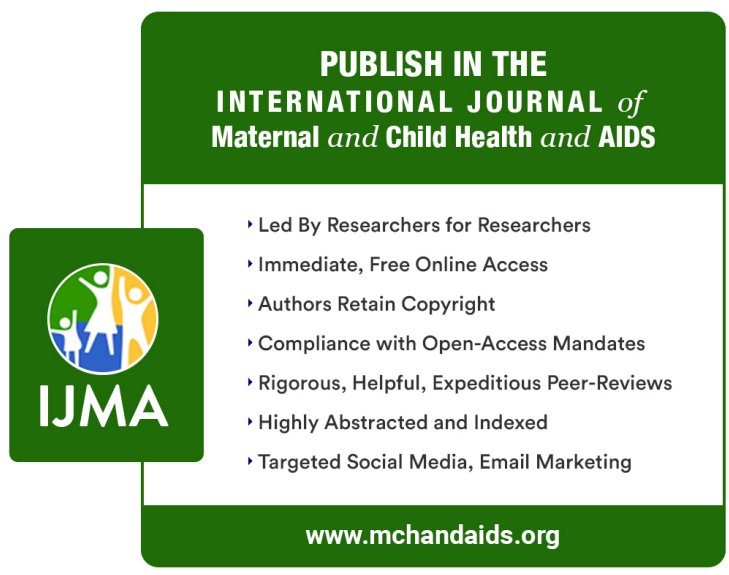

